\title{
A Study on Equity Crowd Funding as a viable option to pre-seed Capital in IT Startups
}

Ravi Thodla* and Seeboli Ghosh Kundu ${ }^{\dagger}$

\begin{abstract}
The rapid growth in Indian economy for the next decade is expected to be spear headed by the startup revolution driven by private enterprises. The startup culture has started showing promising signal of significant contribution in Indian GDP. However, there exist a big gap between the demand and supply in terms of fund availability. This gap can be easily bridged with the help of popularly emerging option known as crowd funding. It is an acceptable fund viable option for the pre-seed capital required in IT startups. This discussion proves the importance of crowd funding under regulatory framework and it has made the study not only relevant but also contemporary.
\end{abstract}

Keywords: Crowd funding, IT Startups, Demand -Supply gap, Pre-seed Capital, Equity based crowd funding.

\section{Introduction}

Raising capital has become a challenge for all kind of startups in the present era. Many entrepreneurs are facing difficulties and landing in failure while raising the capital for their projects. External support is not always easily available while starting a new venture. The traditional modes of raising funds have their own limitations. For example while issuing loan, banks generally ask for

*SRM University, Chennai, India; ravi.thodla@gmail.com

† Bharathiar University, Coimbatore, India; seebolighosh2011@gmail.com 
collateral of the organization which may not always be possible in many cases as the startups may not be able to fulfill the requirement of getting loan. Another problem of raising capital is lack of historical data that includes asymmetric information for investors. One famous mode of finance is to identify venture capitalists who prefer to invest relatively large amounts, only if the project has the potential and is found to be significant. Also, venture capitalists are generally not interested in pre-seed capital and prefer to fund on later stage companies because of the safe return on investment and a more precise valuation process (EY, 2012). All these issues have made crowd funding as one of the most popular tool to raise fund. Even governments have recognized the importance of this mode and the potential of crowd funding to raise capital for startups (Collins, 2012). Compared to the traditional mode of raising capital it is recognized as one of most important and talked about Alternative Avenue for raising capital in pre-seed stage.

\section{Objectives of the study}

- To understand in detail the various funding options available to start -ups in general \& IT Start up in particular.

- To estimate the gap between demand and supply of fund based on publicly available information.

- To explore the possibility of equity based crowd funding as a viable option to finance the pre-seed capital requirement of IT Start ups.

- To consider the pros and cons of regulatory framework of equity based crowd funding.

\section{Literature review}

According to Belleflamme, Lambert and Schwienbacher (2013), crowd funding should be taken as a different financing avenue where funds can be generated from crowd than professional investors like venture capitalists, banks etc. The researchers have also noted that there could be two types of crowds, people who are interested and specialized in taking risky investment and the 
common people who are personally linked with budding entrepreneurs. Their research was based on equity crowd funding and reward based crowd funding. In their study, Belleflamme et al. (2013) have identified that "community benefits" is the advantage of both the crowd funding (equity based and reward base) than the traditional mode of funding. Further Belleflamme et al. (2013), also identified that the size of the entrepreneur's capital requirement makes a huge impact in the crowd funding model selection. Reward based crowd funding will be less in the case of huge capital requirement. In this condition the entrepreneur has no other option than distorting the optimal pricing structure to identify and attract more number of fund providers to pre-order, otherwise the entrepreneur will fail to raise sufficient money to start up the process of production. The qualitative investigation made by Gerber and Hui has identified some answers to the questions of crowd funding. These researchers have conducted their research only based on reward crowd funders and entrepreneurs who are interested in this type of crowd. However their study has not indicated the motivations for other types of crowd funding in order to support any venture (Gerber and Hui (2013). Cholakova and Clarysse (2015) has conducted a research on crowd finding's motivation. Their study indicated the impact of having a project on both reward and equity based crowd funding campaign simultaneously in order to get the fund. They have come up with the finding that the aim of crowd funding is not only to channelize the fund or to support the entrepreneur but to support a cause (Cholakova and Clarysse, 2015). This research has significantly contributed in the crowd funding research as they have identified important relationship between desire to collect reward and the decision to pledge. They have identified trust factor as a very important variable in case of crowd funding. The credibility of fund seekers plays a very significant role in case of crowd funding. The research of Gerber and Hui (2013) is not only applicable for reward based crowd funding but also applicable for equity based crowd funding. 


\section{Methodology}

This paper is exploratory in nature and can be viewed as a concept paper that provides the spring boat for detailed research on equity based crowd funding.

\section{Data Source}

Being a preliminary study, this paper is entirely based on publicly available Secondary data sources from journals, periodicals, research articles and web links. Primary data has not been considered for the time and may be for the part of further research in the near future. Analysis is mainly done through parametric measure like co-relation and regression analysis.

\section{Expected Learning outcomes}

It is expected that there is likely to be a high degree of relationship between the increase in demand supply gap for pre-seed capital and the growth of equity based crowd funding. It is also likely that equity based crowd funding may become a greatly preferred model for funding in the pre-seed capital requirement of IT start up.

\section{Analysis and Interpretation}

The concept of crowd funding is relatively new in the country like India and mostly unknown among the startup population. The never ending struggle to raise funds for pre-seed capital requirements of startup continuous and they face difficulties to scale up to the next level. An analysis of available data is very revealing and lead to identification of new and virgin territories of possible fund raising, equity based crowd being one of them.

\begin{tabular}{llr}
\hline \multicolumn{1}{c}{ Period } & \multicolumn{1}{c}{ Vertical Distribution } & Amount (USD) \\
\hline $2016-17$ & Consumer Internet & 273743000 \\
$2016-17$ & e-commerce & 39030000 \\
$2016-17$ & Logistic & 23000000 \\
$2016-17$ & Technology & 109283500 \\
\hline
\end{tabular}

The chart displays the debit pattern of Indian startup funding during the year 2016-2017. The total amount 445 million has flown in to this segment which indicates a good beginning. An analysis of vertical wise distribution shows that the major chunk of the 
amount has flown in to either technology or technology driven business such as e-commerce and logistic. Significantly many of these startups work in the field of technology either directly or indirectly. For instance, one hundred and nine million dollar USD has found its way into technology startups, the rest of the money has been mobilized for investment in e-commerce and logistics whose back bone is driven by back office technology (336 million in USD). However, there continues to be a wide gap between the market demand and supply of funds for the Indian IT or IT driven startups that is growing wider by the day. Especially in the light of astounding enthusiasm among the youth who are infected by the startup fever, the race between demand and supply seems to be mismatched heavily with the tilt growing more towards the demand side.

The latest data that is available from reliable sources like kick starter and other crowd funding platforms put the estimated demand for pre-seed startup capital at around three hundred billion US dollars all over the world and at least $30 \%$ of this is attributed to Indian startups. According to government sources there has been a significant increase in foreign direct investment in India at $60 \%$ that compares favorably with only $19 \%$ as the global average. But most of the money goes towards established companies in the form of collaboration, join venture or equity participation in line with government norms that govern FDI. But the real growth story is likely to be profiled by the MSME startups that are finding it increasingly difficult to fund their pre-seed capital requirements to prove their technical and financial viability (Agrawal, 2013).

Angel Investors who are not visible either on line or off line and who invest through intermediaries fund startups that have already proved themselves with a capital of between 75 lakhs and 3 crores in India. Further funding required to scale up comes from venture capitalists who look at the project with minimum capital requirement of minimum 3 cores and up to 10 crores. Private equity comes predetermined with exit strategies and provides funding for these startups above 10 cores and enables them to move to the next level. Although the issue of valuation and size of the state in equity is still an elusive bargain, there is still a lot of 
interest among the leading private equity players in the Indian startup story. For example, Black Stone picked up 10\% stake in Aanathar resort at the foot of Himalayas at a captive valuation in 2009. Similarly, Warren Buffets' Berkshire Insurance invested 400 million in a forging company in Chandapura, Bangalore, Karnataka, in the year 2011. Similarly many search biggies in private equity are moving towards India in a big way.

However, at the bottom of the pyramid there is still struggle and uncertainty about avenues and quantum of funding for the most needed pre-seed capital for young entrepreneurs. Particularly there is a great deal of enthusiasm among student entrepreneurs' and technocrats to start their own ventures in the application, gaming and other internet based products. In the recent years it is estimated that at least $17 \%$ of the Indian GDP (Gross Domestic Product) may come from these services in the next four years ending in 2020. The dilemma of bridging the gap between demand and supply calls for new and unexplored funding option for meeting the pre-seed capital requirement of this enthusiastic youth startup population.

\section{Equity Based Crowd- Funding: An Emerging Option}

A country like India is always exploring different funding options. It is true startups are embracing any innovative model including the emerging concept of crowd funding. However, it is not because we are plagued by policy paralyses but it is because of our concern to protect public interest. In that sense we are at least 10 years late in seriously considering equity based crowd funding as a viable funding avenue, though there are already at least 10 online crowd funding platforms that have started functioning in India. No need to say that it has evoked such amount of heat in the market that SEBI has thought it fit to initiate a discussion on this issue, to explore the need for bringing crowd funding under the regulatory framework.

Equity based crowd funding is not simple but an effective Eplatform that may revolutionize the way startups can gain access to pre-seed capital. It is now much easier for small businesses to raise one rupee each from let us say 50 lakh people or Rs.10 from 5 lakhs people with almost negligible risk for capital to the investors at the 
worst these investors may either write off the contribution as donation or simply the cost of hedging. But, when such companies that received the funding prove to be successful and scale up to higher levels, they promote greater interest among the retailer investors. This may prove to be a much cheaper option in terms of cost of raising funds because not much money needs to be spent on publicity as in the case of an Initial Public Offering (IPO) or bank borrowing or borrowing from authorized financial institutions. Such processes, as opposed to crowd funding, might also cause undue delay owing to approvals and sanctions. For the time being, it may not really be necessary to bring crowd funding under stringent regulation as suggested by many critics. However, online platforms for crowd funding need to be closely monitored through the establishment of mandatory requirements for regular and transparent reporting to at least the Ministry of Small Scale Industries, if not to the Registrar of the Companies or SEBI. Strangling such innovative initiatives with suffocating bureaucratic red-tapism and complicated regulatory compliance may defeat the very purpose of such avenues and startups will be the only sufferers (Collins, 2012).

\section{Conclusion}

Progress and innovation are adjoining twins that are attached to each other. Though many have considered innovation as an invitation to risk through your door front; it has not stopped the world from progressing through innovation (Ahlers, 2014).Since the advent of the free market economy, there has been a rapid progress in information technology, telecommunication and financial services and instruments that the world has witnessed in the last fifty years. The economic and financial disasters that we have witnessed here and there triggered by disruptive innovation should only make us more cautiously optimistic and evolve a system with preventive checks and balances. As warren buffet once said, "The simplest thing to do to avoid risk is not to do anything. But in the process, we are inviting greater risk of not doing anything at all." It is better to explore, experiment and learn from failures than discard any innovation outright. Seen in that light, 
equity based crowd funding could well be the next wave after Alwin Taffler's third wave.

\section{References}

Agrawal, A., Catalini, C., \& Goldfarb, A. (2013). Some Simple Economics of Crowd funding. National Bureau of Economic Research, w19133, 146.

Ahlers, G. K., Cumming, D., Günther, C., \& Schweizer, D. (2015). Signaling in Equity Crowd funding. Entrepreneurship Theory and Practice, 39(4), 955-980.

Belleflamme, P., \& Peitz, M. (2007). Asymmetric Information and Over Investment in Quality. European Economic Review, 66, 127-143.

Belleflamme, P., Lambert, T., \& Schwienbacher, A. (2010, June). Crowd funding: An industrial organization perspective. Proceedings from the workshop "Digital Business Models: Understanding Strategies", held in Paris on June, 25-26.

Collins, L., \& Pierrakis, Y. (2012). The venture crowd: crowd funding equity investments into business. Nesta, 1-34.

Cholakova,M. and Clarysse, B. (2015). Does the Possibility to Make Equity Investments in crowd funding Projects Crowd Out Reward-Based Investments?.Entrepreneurship Theory and Practice, 39(1), 145-172.

Cull, R., Davis, L. E., Lamoreaux, N. R., \& Rosenthal, J.-L. (2006). Historical Financing of Small-and Medium-size Enterprises. Journal of Banking and Finance, 30, 3017-3042.

Ernst\&Young. (2012, June). Funding the Funture: Access to Finance for Entrepreneurs in the G20. Retrieved on March 5, 2015.

Gerber, E. and Hui, J. (2013). Crowd funding: Motivations and Deterrents for Participation.

Association for Computing Machinery. (1994).ACM Transactions on Computer-Human Interaction.20(6), Article No.: 34.

EY. (2013, 04.04). Global Venture Capital funds may turn the corner in 2013.

Felländer, A., Ingram, C., \& Teigland, R. (2015). Sharing Economy: embracing change with caution.

Gregory, B. T., Rutherford, M. W., Oswald, S., \& Gardiner, L. (2005). An Empirical Investigation of the Growth Life Cycle Theory of Small Firm Financing. Journal of Small Business Management, 43(4), 382-392.

Hall, B. H. (2002). The Financing of Research and Development. Oxford Review of Economic Policy, 18(1), 35-51. 
Lehner, O. M. (2013). Crowd funding Social Ventures: A Model and Research Agenda. Venture Capital Journal, 15(4), 289-311.

Mollick, E. (2013). Swept away by the crowd? Crowd funding, venture capital, and the selection of entrepreneurs. Venture Capital and the Selection of Entrepreneurs, 1-39. 